\title{
ROBUST INTEGER HAAR WAVELET BASED WATERMARKING USING SINGULAR VALUE DECOMPOSITION
}

\author{
Prajanto Wahyu Adi, and Farah Zakiyah Rahmanti \\ Faculty of Computer Science, Universitas Dian Nuswantoro (UDINUS), Jalan Imam Bonjol, No.207, \\ Semarang, 50131, Indonesia \\ E-mail: prajanto@dsn.dinus.ac.id,farah_zakiyah@dsn.dinus.ac.id
}

\begin{abstract}
This paper proposed a hybrid watermarking method that used dither quantization of Singular Value Decomposition (SVD) on average coefficients of Integer Haar Wavelet Transform (IHWT). The watermark image embeds through dither quantization process on singular coefficients value. This scheme aims to obtain the higher robustness level than previous method which performs dither quantization of SVD directly on image pixels value. The experiment results show that the proposed method has proper watermarked images quality above $38 \mathrm{~dB}$. The proposed method has better performance than the previous method in term of robustness against several image processing attacks. In JPEG compression with Quality Factor of 50 and 70, JPEG2000 compression with Compression Ratio of 5 and 3, average filtering, and Gaussian filtering, the previous method has average Normalized Correlation (NC) values of $0.8756,0.9759,0.9509,0.9905,0.8321$, and 0.9297 respectively. While, the proposed method has better average NC values of $0.9730,0.9884,0.9844,0.9963,0.9020$, and 0.9590 respectively.
\end{abstract}

Keywords: watermarking, SVD, integer wavelet transform, dither quantization

\begin{abstract}
Abstrak
Paper ini mengusulkan metode watermarking yang menggabungkan kuantisasi dither SVD pada nilai koefisien rata-rata IHWT. Citra watermark disisipkan melalui proses kuantisasi dither pada nilai koefisien singular. Skema ini dilakukan untuk memperoleh tingkat ketahanan yang lebih tinggi dari metode sebelumnya yang melakukan kuantisasi dither SVD secara langsung pada nilai piksel citra. Hasil percobaan menunjukkan bahwa metode yang diusulkan mempunyai kualitas citra ter-watermark yang layak diatas 38dB. Metode yang diusulkan mempunyai kinerja lebih baik dari metode sebelumnya dalam hal ketahanan terhadap beberapa serangan citra. Dalam kompresi JPEG dengan Quality Factor 50 dan 70, kompresi JPEG2000 dengan Compression Ratio 5 dan 3, average filtering, dan gaussian filtering, metode sebelumnya menghasilkan nilai Normalized Correlation (NC) rata-rata berturut-turut sebesar 0.8756, 0.9759, 0.9509, 0.9905, 0.8321, dan 0.9297. Sementara, metode yang diusulkan menghasilkan nilai NC rata-rata yang lebih baik sebesar 0.9730, 0.9884, 0.9844, 0.9963, 0.9020, dan 0.9590 berturut-turut.
\end{abstract}

Kata Kunci: watermarking, SVD, integer wavelet transform, dither quantization

\section{Introduction}

The rapid growth of the Internet and computer networks led to ease of distribution process of digital medium such as audio, video, and digital image [1-2]. It provides convenience in sharing digital content. However, the ease of copying medium without regard to the ownership, poses a threat on copyright protection [3]. Digital water-marking system provides a solution to protect the copyright of digital content [4]. It is able to hide proprietary information into digital medium in order to provide proof of ownership. In addition, the application of digital watermarking has been expanded to the several fields, such as: authentication, broadcast monitoring, and finger printing [3]. Generally, wa-termarking can be classified in-to several types. A widely used classification is based on domain that is used. Watermarking can be classified into spati-al and transform domain method. The spatial me-thods embeds watermark directly on image pixels which results in low computational complexity, but vulnerable against image processing attack. Instead, the transform domain methods have more resistance against many attacks [3-6].

Several studies about transform domain based watermarking have been carried out, such as Discrete Cosine Transform (DCT) [7-8], Discrete Wavelet Transform (DWT) [5,9], Lifting Wavelet 

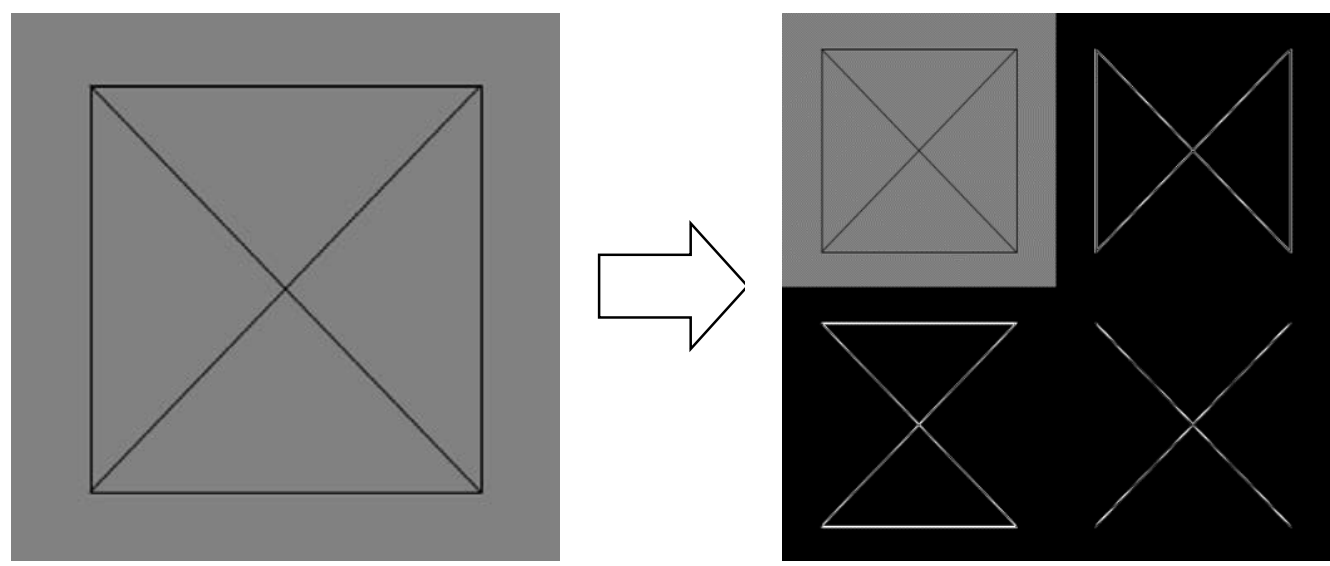

Figure 1. Integer Haar Wavelet Transformation $\mathrm{HH}$

Transform (LWT) [4], and Integer Wavelet Transform (IWT) [3] and [10]. DCT is a popular method, but it can cause damage on image when inserting large size of watermark [11]. Alternatively, DWT is able to compute image features at multiple resolution level which can improve the imperceptibility and robustness of watermarked image [11]. However, the floating point coefficients of DWT will induce reversibility problem that occur after transformation [4]. The LWT and IWT are the second generation wavelet transform methods which developed from DWT through a lifting scheme. These methods can avoid the floating point problem of DWT [12] and able to make watermarking scheme more efficient [4]. This paper proposed the use of Integer Haar Wavelet Transform (IHWT) coefficients as the values of SVD, due to numerical advantages of IHWT [13].

The following sections of this paper are organized as follows: The process of embedding and extraction of the proposed method are explained in Section 2. In Section 3, the experiment results, performance comparison, analysis and discussion are presented. Finally, the conclusions are descrybed in Section 4.

IHWT is the second generation of wavelet transform which is developed from Discrete Haar Wavelet Transform (DHWT) via lifting scheme by $\mathrm{Xu}$ et al. [14]. Basically, the wavelet transformation on digital image is used to decompose image with size of $M \times N$ into four groups of wavelet coefficients with size of $M / 2 \times N / 2$, namely $L L$, $\mathrm{HL}, \mathrm{LH}$, and HH. Those wavelets coefficients are often called as sub bands. The main idea of wavelet transformation on digital image is by applying low pass filter and high pass filter in horizontal and vertical orders. LL is produced from low pass filtering in both horizontal and vertical order. In $\mathrm{HL}$, high pass filter is applied in horizontal order followed by low pass filter in vertical order and vice versa for LH. Afterwards applying high pass filter in both horizontal and vertical orders to generate HH. IHWT performs decomposition using 4 filters which generates from low pass and high pass filters as given by equation(1) until equation (4).

Figure 1 shows that the image is decomposed into four wavelet sub band namely: LL at the top left, HL at the top right, $\mathrm{LH}$ at the bottom left, and $\mathrm{HH}$ at the bottom right position of the wavelet sub bands. LL is the average coefficients values that contain the average value of image, this wavelet's sub band contain the significant values of image so it has high robustness in maintaining information contained therein $[13,15]$. Whereas, the $\mathrm{HL}, \mathrm{LH}$, and are the less significant coefficient value of that contain the edge are of the images. HL is used to removes the horizontal edge of image and let the vertical and diagonal edge of image. Otherwise, LH eliminates the vertical part and left the horizontal and diagonal parts. While, the $\mathrm{HH}$ is intended to removes both vertical and horizontal edge of the image.

Integer Haar Wavelet Transform (IHWT) decompose 2x2 non-overlapping block of image below into wavelet coefficients as given by equation(1) to equation(4).

$$
\left[\begin{array}{cc}
I_{m, n} & I_{m, n+1} \\
I_{m+1, n} & I_{m+1, n+1}
\end{array}\right]
$$

$L L=\left[\frac{\left[\frac{I_{m, n}+I_{m, n+1}}{2}\right]+\left[\frac{I_{m+1, n}+I_{m+1, n+1}}{2}\right]}{2}\right]$

$$
\begin{aligned}
& \boldsymbol{H L}=\left[\frac{\boldsymbol{I}_{\boldsymbol{m}, \boldsymbol{n}}-\boldsymbol{I}_{\boldsymbol{m}, \boldsymbol{n}+\mathbf{1}}+\boldsymbol{I}_{\boldsymbol{m}+\mathbf{1 , n}}-\boldsymbol{I}_{\boldsymbol{m + 1 , n + 1}}}{\mathbf{2}}\right] \\
& L H=\left[\frac{I_{m, n}+I_{m, n+1}}{2}\right]-\left[\frac{I_{m+1, n}+I_{m+1, n+1}}{2}\right]
\end{aligned}
$$


28 Jurnal Ilmu Komputer dan Informasi (Journal of Computer Science and Information), Volume 9, Issue 1, February 2016

$$
H H=I_{m, n}-I_{m, n+1}-I_{m+1, n}+I_{m+1, n+1}
$$

where, $I_{m, n}$ is a pixel value of every block of image at row $m$ and column $n$.

The watermark is embedded on LL sub-band to gain high robustness; otherwise it can be embedded to HL, LH, or HH for high imperceptibility. After the embedding, the block of watermarked image ( $\left.I^{\prime}\right)$ below

$$
\left[\begin{array}{cc}
I_{m, n}^{\prime} & I_{m, n+1}^{\prime} \\
I_{m+1, n}^{\prime} & I_{m+1, n+1}^{\prime}
\end{array}\right]
$$

is reconstructed from wavelet coefficients as the following equation(5) to equation(8):

$$
\begin{gathered}
I_{m, n}^{\prime}=L L+\left\lfloor\frac{L H+1}{2}\right\rfloor+\left\lfloor\frac{H L+\left\lfloor\frac{H H+1}{2}\right\rfloor+1}{2}\right\rfloor \\
I_{m, n+1}^{\prime}=I_{m, n}^{\prime}-\left(H L+\left\lfloor\frac{H H+1}{2}\right\rfloor\right) \\
I_{m+1, n}^{\prime}=L L+\left\lfloor\frac{L H+1}{2}\right\rfloor-L H+\left\lfloor\frac{H L+\left\lfloor\frac{H H+1}{2}\right\rfloor-H H+1}{2}\right\rfloor \\
I_{m, n+1}^{\prime}=I_{m+1, n}^{\prime}-\left(H L+\left\lfloor\frac{H H+1}{2}\right\rfloor-H H\right)
\end{gathered}
$$

Equation(5) until equation(8) shows that IHWT is able to maintain the lost information due truncateon process in equation(1) until (4) by the addition of integer value of 1 in the reconstruction process. This lifting scheme is able to restore the missing value in watermarked image.

\section{Methods}

In our method, the watermark bits are embedded on singular value of average coefficients using dither quantization as shown in Figure 2. This scheme aimed to obtain the higher robustness level than previous method by Mohan and Kumar [16], which performs dither quantization directly on singular value of image pixel.

\section{Watermark Embedding}

First of all, apply IHWT using equation(1) until equation(4) on original image to get LL, HL, LH, and $\mathrm{HH}$. Then perform SVD transformation on each 8x8 block of average coefficients LL to get matrices $U_{b}, S_{b}$, and $V_{b}$ of block $b$ as given by equation(9).

$$
S V D_{b}\left(L L_{b}\right)=U_{b} S_{b} V_{b}
$$

where $S_{b}$ is a singular matrices, $U_{b}$ and $V_{b}$ are the orthogonal matrices of block $b$.

Afterwards, calculate the lower bound and upper bound of each quantization step as formulated using equation(10) and equation(11).

$$
\begin{aligned}
& l_{i}=\min S+q(i-2) \\
& u_{i}=\min S+q(i-1)
\end{aligned}
$$

where $q$ is quantization step size, $\min S$ is minimum value of largest singular value $S_{1 b}$ on entire blocks, $l_{i}$ and $u_{i}$ are the upper bound and lower bound of quantization step $i$, for $i=1,2, \ldots, q$.

Once the bounds are calculated, generate a quantization table from $l_{i}$ and $u_{i}$ of each quantization step. Embed watermark by altering $S_{1 b}$ according to watermark bit value for $l_{i} \leq S_{1 b}<u_{i}$

$$
S_{1 b}^{\prime}= \begin{cases}\left(\left(l_{i}+u_{i}\right) / 2+l_{i}\right) / 2 & \text {, if } w=1 \\ \left(\left(l_{i}+u_{i}\right) / 2+u_{i}\right) / 2 & \text {, if } w=0\end{cases}
$$

where $\boldsymbol{S}_{\mathbf{1 b}}^{\prime}$ is the new largest singular value of block $b$, and $w$ is the watermark bit value. Then perform inverse SVD on each block to get watermarked average coefficient $L L$,

$$
L L_{b}^{\prime}=U_{b} S_{b}^{\prime} V_{b}^{T}
$$

Where $\boldsymbol{V}_{\boldsymbol{b}}^{\boldsymbol{T}}$ is the conjugate transpose of $V_{b}$. Lastly, apply Inverse IHWT using equation (5) to equation(8) on LL', HL, LH, and HH to get watermarked image.

\section{Watermark Extraction}

Watermark extraction process is done by arranging the singular values of average coefficients into the corresponding quantization step in quantization table. It is then used to obtain the watermark bit value based on the difference of singular values toward upper bound and lower bound: 1) apply IHWT transformation using equation(1) until equation(4) on watermarked image to get LL, HL, $\mathrm{LH}$, and $\mathrm{HH} ; 2$ ) perform SVD transformation on each 8x8 block of LL to get matrices $U_{b}, S_{b}$, and $V_{b}$; 3) use the quantization table as a key to extract watermark image; 4) extract watermark bit value on each block to get the watermark image using equation(14). 


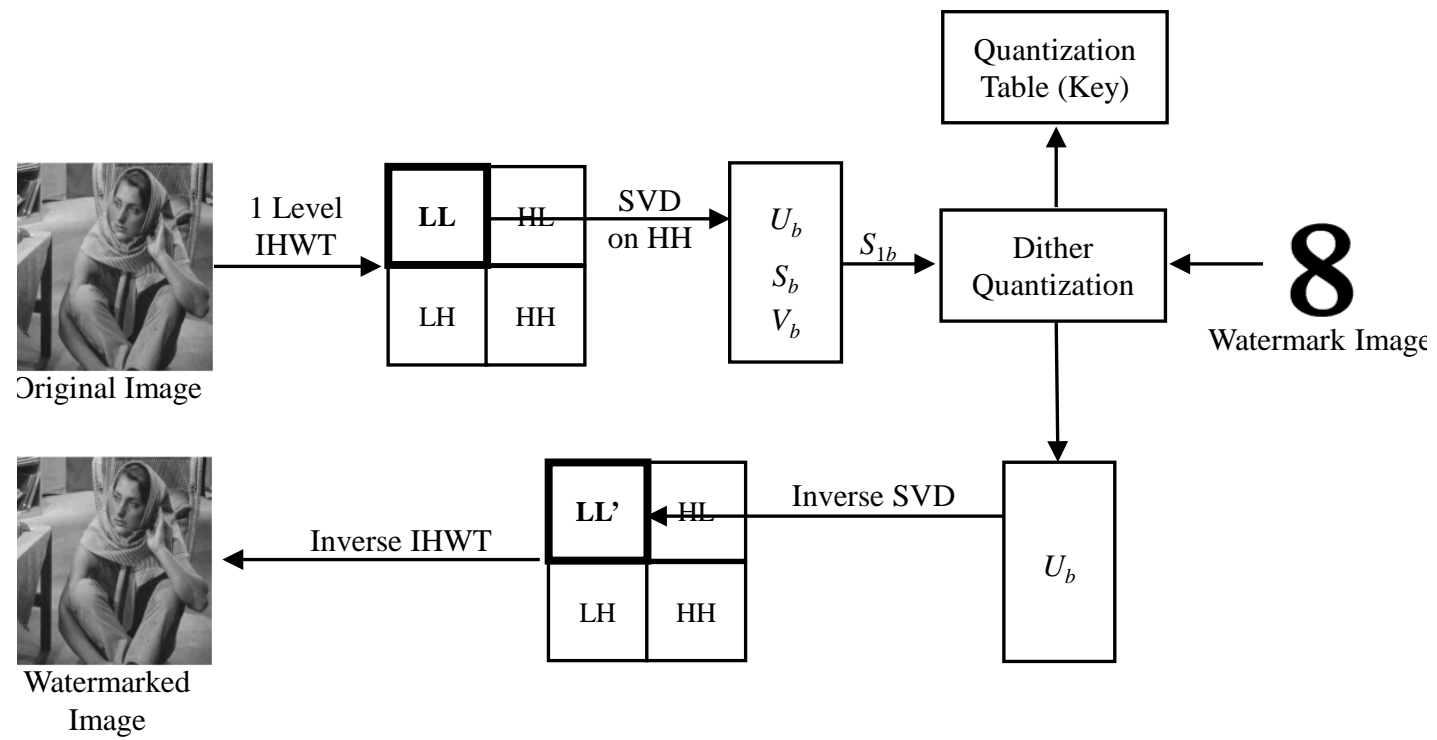

(a)

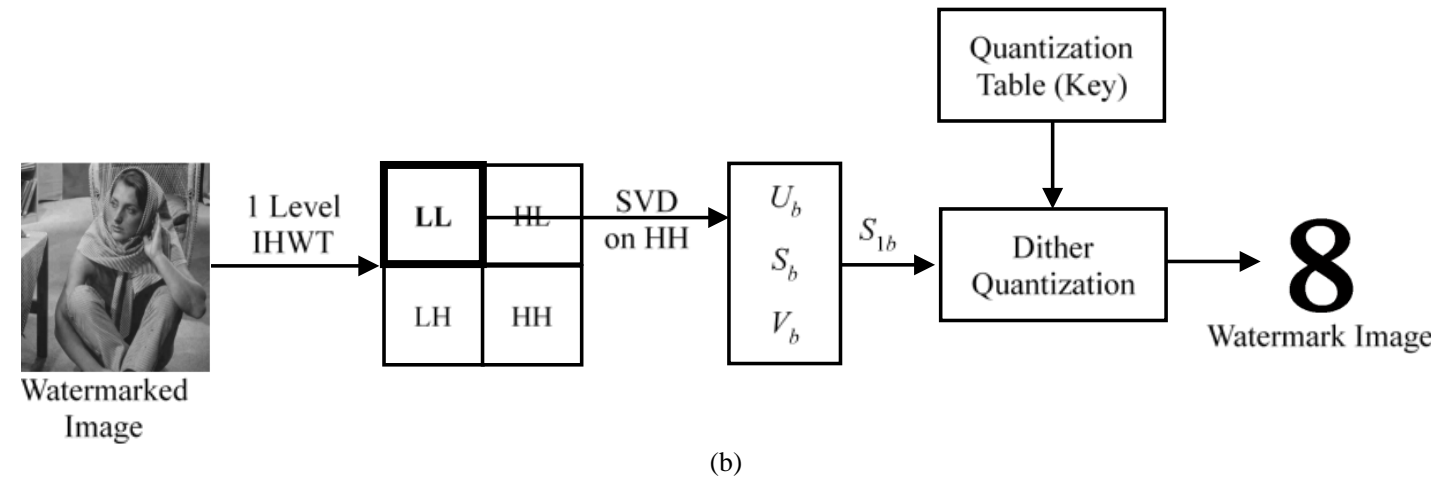

Figure 2. The proposed method: (a) embedding and (b) extraction

$$
w_{b}=\left\{\begin{array}{lll}
1 & \text {, if } & l_{i} \leq S_{1 b}<\left(l_{i}+u_{i}\right) / 2 \\
0 & \text {,if } \quad\left(l_{i}+u_{i}\right) / 2 \leq S_{1 b}<u_{i}
\end{array}\right.
$$

Where $w_{b}$ is the watermark value $b$, and $S_{1 b}$ is the largest singular value of block $b$ for $l_{i} \leq S_{1 b}<u_{i}$.

\section{Results and Analysis}

This research uses 6 standard grayscale image within bitmap format (.bmp) and size of $512 \times 512$ pixels as original images and a binary image as watermark image as shown in Figure 3 and Figure 5.

\section{Watermarked Image Quality}

Based on previous research [16], watermark image is embedded using step size of 60 in order to get optimum results [16]. The quality of watermarked images are measured using standard Peak Signal to Noise Ratio (PSNR), and Structural Similarity (SSIM) [17].

\section{Performance Comparison}

The proposed method is compared with the previous method by Mohan and Kumar [16] in terms of the robustness of watermark images and the computational complexity of the methods in embedding and extraction.

\section{Robustness}

Several popular attacks on watermarked images, namely: JPEG compression, JPEG2000 compression, average filtering, and median filtering are used in this experiment. Performances of both methods are measured using Normalized Correlation (NC) which is widely used in field of watermarking. The first experiment is carried out to compare the robustness of the both methods against JPEG compression with the standard Quality Factor (QF) of 50 and 70.

Table 2 and Figure 6 show that the previous method has low robustness against JPEG compression attack with QF of 50. Meanwhile, the pro- 


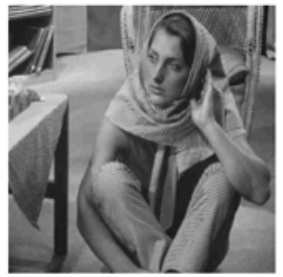

Barbara

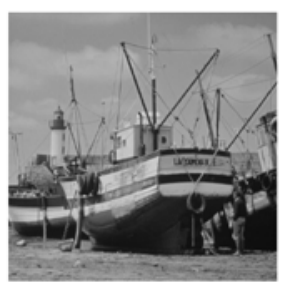

Boat

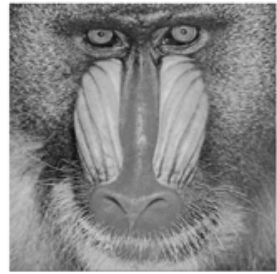

Baboon

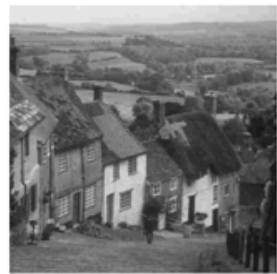

Goldhill

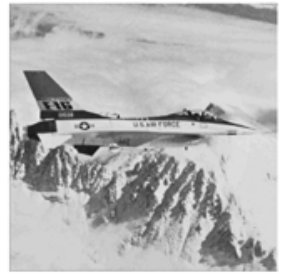

Jet

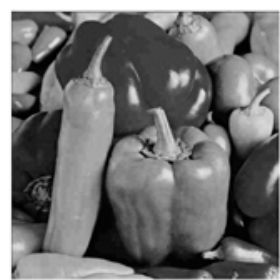

Peppers

Figure 3. Original images

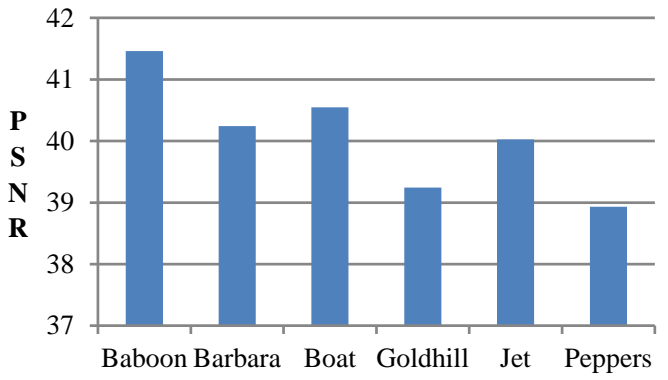

(a)

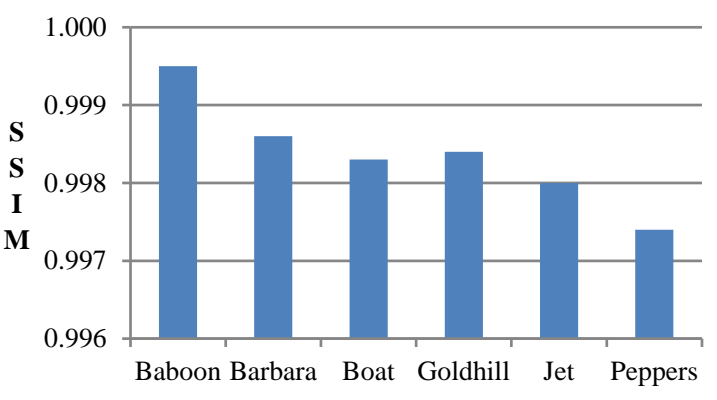

(b)

Figure 4. Watermarked Images Quality in (a) PSNR and (b) SSIM

\section{8}

Figure 5. Watermark image

posed method has higher robustness level than previous method. The proposed method even almost reached perfect robustness level at QF of 70.

The next comparison is deal with JPEG 2000 compression attack. The decent Compression Ratio (CR) of 5 and 3 are used to compress the water-marked images.

JPEG2000 attack does not give significant damage on watermark images as shown in Table 3 and Figure 7. Although the both methods have good robustness level, the proposed method still outperforms the previous method. The proposed method has perfect NC value of 1 in test of Gold-hill and Peppers images within compression ratio of 3 . The last experiment is test the robustness against Average Filtering (AF) and Gaussian Filtering (GF) attacks. The average filter size used is $3 \times 3$, while the Gaussian filter have sigma value of 0.5 and filter size of $3 \times 3$ which is the default value of the filters. Table 4 and Figure 8 show that the both filtering attack gives significant dam-age on watermark images. It also shows that pro-posed method has better robustness level against average and Gaussian filtering attacks.

The proposed method has higher robustness level against such compression and filtering attacks. Table 5 shows that the extracted water-mark images of the proposed method has better visual quality than the previous method.

\section{Computational Complexity}

Test of computational time was conducted to measure performance of the proposed method against the previous method in embedding and extraction processes. The test was conducted in a laptop PC with second generation Intel Core i3- 2310M quad core processor $2.1 \mathrm{GHz}$ of clock and 6GB of RAM. The execution times of the both methods are measured in milliseconds (ms). 
TABLE 1

\begin{tabular}{ccc}
\multicolumn{3}{c}{ WATERMARKED IMAGES QUALITY } \\
\hline Images & PSNR & SSIM \\
\hline Baboon & 41.4615 & 0.9995 \\
Barbara & 40.2440 & 0.9986 \\
Boat & 40.5464 & 0.9983 \\
Goldhill & 39.2421 & 0.9984 \\
Jet & 40.0268 & 0.9980 \\
Peppers & 38.9337 & 0.9974 \\
\hline
\end{tabular}

TABLE 2

ROBUSTNESS AGAINST JPEG COMPRESSION

\begin{tabular}{ccccc}
\hline \multirow{2}{*}{ Images } & \multicolumn{2}{c}{ SVD[16] } & \multicolumn{2}{c}{ Proposed } \\
\cline { 2 - 5 } & QF 50 & QF 70 & QF 50 & QF 70 \\
\hline Baboon & 0.8291 & 0.9643 & 0.9474 & 0.9846 \\
Barbara & 0.8579 & 0.9692 & 0.9743 & 0.9986 \\
Boat & 0.8622 & 0.9616 & 0.9631 & 0.9690 \\
Goldhill & 0.9047 & 0.9904 & 0.9891 & 0.9994 \\
Jet & 0.8832 & 0.9776 & 0.9697 & 0.9794 \\
Peppers & 0.9165 & 0.9922 & 0.9943 & 0.9994 \\
\hline Average & 0.8756 & 0.9759 & 0.9730 & 0.9884 \\
\hline
\end{tabular}

TABLE 3

ROBUSTNESS AGAINST JPEG2000 COMPRESSION

\begin{tabular}{lcccc}
\hline \multirow{2}{*}{ Images } & \multicolumn{2}{c}{ SVD[16] } & \multicolumn{2}{c}{ Proposed } \\
\cline { 2 - 5 } & CR 5 & CR 3 & CR 5 & CR 3 \\
\hline Baboon & 0.7881 & 0.9507 & 0.9192 & 0.9795 \\
Barbara & 0.9650 & 0.9960 & 0.9955 & 0.9994 \\
Boat & 0.9903 & 0.9989 & 0.9981 & 0.9994 \\
Goldhill & 0.9808 & 0.9992 & 0.9981 & 1.0000 \\
Jet & 0.9935 & 0.9992 & 0.9968 & 0.9994 \\
Peppers & 0.9877 & 0.9987 & 0.9987 & 1.0000 \\
\hline Average & 0.9509 & 0.9905 & 0.9844 & 0.9963 \\
\hline
\end{tabular}

TABLE 4

ROBUSTNESS AGAINST FILTERING

\begin{tabular}{lcccc}
\multicolumn{4}{c}{ ROBUSTNESS AGAINST FILTERING } \\
\cline { 2 - 5 } Images & \multicolumn{2}{c}{ SVD[16] } & \multicolumn{2}{c}{ Proposed } \\
\cline { 2 - 5 } BF & GF & AF & GF \\
\hline Baboon & 0.7328 & 0.8696 & 0.8494 & 0.9471 \\
Boat & 0.8340 & 0.9283 & 0.9068 & 0.9451 \\
Goldhill & 0.8605 & 0.9608 & 0.9168 & 0.9703 \\
Jet & 0.8755 & 0.9368 & 0.9071 & 0.9524 \\
Peppers & 0.8873 & 0.9555 & 0.9325 & 0.9775 \\
\hline Average & 0.8381 & 0.9297 & 0.9020 & 0.9590 \\
\hline
\end{tabular}

The experiment results in Table 6 and Figure 10 shows that the proposed method has slower embedding process with average value of $1870 \mathrm{~ms}$, while the previous method has average embedding time of 740ms. However, the proposed method has faster extraction process with average time of $278 \mathrm{~ms}$.

IHWT have integer precision on the basic principle of wavelet transformation which able to perform down sampling as given by equation(1)

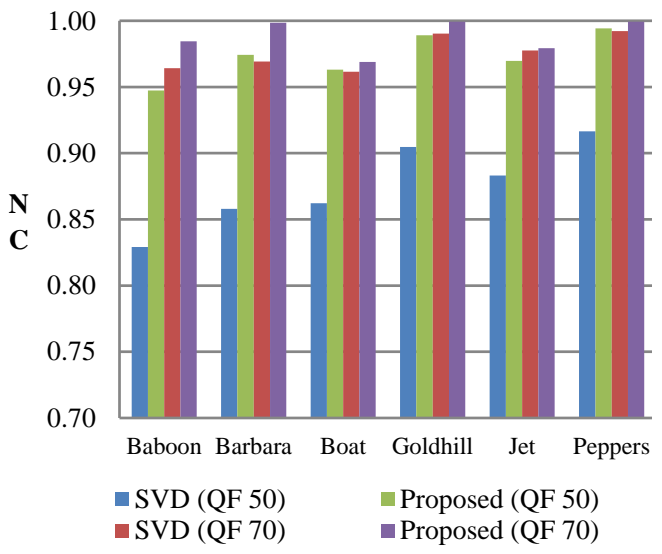

Figure 6. Robustness against JPEG Compression

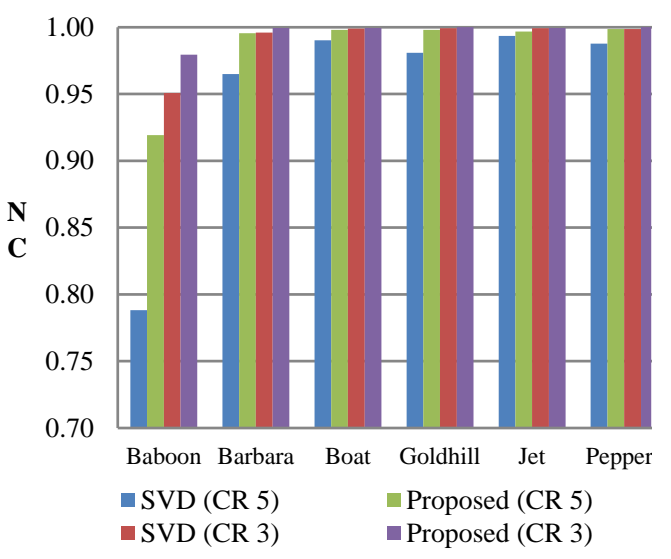

Figure 7. Robustness against JPEG2000 Compression

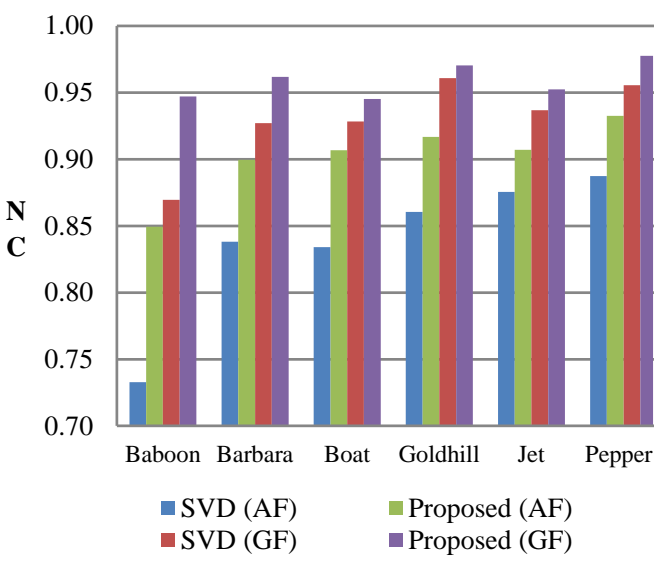

Figure 8. Robustness against Filtering

until (4). The image pixels value $I_{m, n}, I_{m+1, n}, I_{m, n+1}$, $I_{m+1, n+1}$ are down sampled into single coefficient value. The dither quantization of singular value of wavelet coefficients will reduce watermark image size from $M \times N$ into $M / 2 \times N / 2$ due to down sampling scheme of IHWT. The smaller size of watermark will increase the density of coefficients that used as singular value in embedding process 
32 Jurnal Ilmu Komputer dan Informasi (Journal of Computer Science and Information), Volume 9, Issue 1, February 2016

as given by equation(12). It also reduces the computational complexity in extraction of watermark. Increasing number of coefficients used in SVD will improve the robustness of watermark image as well.

The watermark is embeds on LL coefficients which have lowest frequency among all wavelet coefficients. LL is derived from average value of image as given by equation(1), so it has low level of disparity or frequency. A low wavelet coefficient is able to maintain the value therein, thus increase the robustness of watermark image. The down sampling scheme and the use of low frequency coefficients are the two main factors that

TABLE 6

EMBEDDING AND EXTRACTION TIMES

\begin{tabular}{lcccc}
\hline \multirow{2}{*}{ Images } & \multicolumn{2}{c}{ SVD[16] } & \multicolumn{2}{c}{ Proposed } \\
\cline { 2 - 5 } & Embed & Extract & Embed & Extract \\
\hline Baboon & 748 & 336 & 1821 & 270 \\
Barbara & 719 & 339 & 1879 & 272 \\
Boat & 713 & 341 & 1857 & 274 \\
Goldhill & 765 & 331 & 1868 & 271 \\
Jet & 756 & 333 & 1882 & 281 \\
Peppers & 740 & 372 & 1914 & 304 \\
\hline Average & 740 & 342 & 1870 & 278 \\
\hline
\end{tabular}

cause the superiority of the proposed method over the previous method by Mohan and Kumar.

\section{Conclusion}

This paper proposed a hybrid watermarking method that used SVD on average coefficients of IHWT. The watermark image is embeds through dither quantization process on singular coefficie-

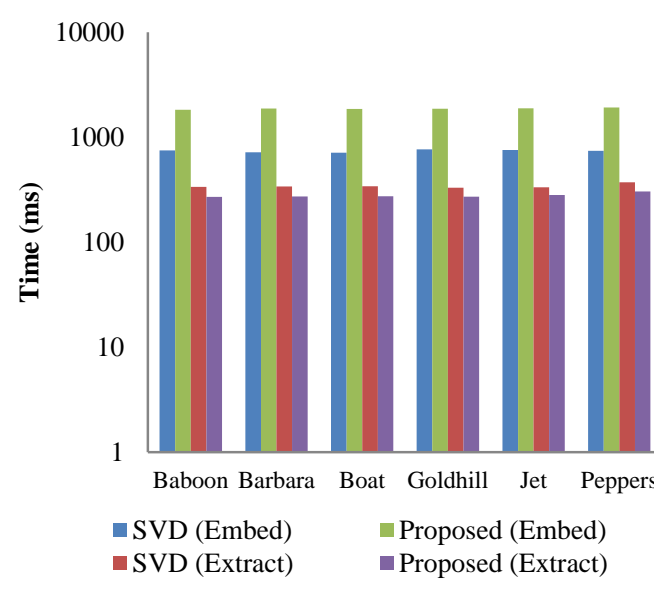

Figure 8. Robustness against Filtering

TABLE 5

EXTRACTED WATERMARK IMAGES

\begin{tabular}{|c|c|c|c|c|c|c|c|}
\hline \multirow{2}{*}{ Methods } & \multirow{2}{*}{ Attacks } & \multicolumn{6}{|c|}{ Images } \\
\hline & & Baboon & Barbara & Boat & Goldhill & Jet & Peppers \\
\hline \multirow{9}{*}{ SVD [16] } & JPEG & & & & & & \\
\hline & QF 50 & & & & & & \\
\hline & JPEG & & & & & & \\
\hline & Q 1.70 & & & & & & \\
\hline & $\begin{array}{l}\text { JPEG2000 } \\
\text { CR } 5\end{array}$ & & & & & & \\
\hline & JPEG2000 & & & & & & \\
\hline & Average & & & 8 & & & \\
\hline & Filtering & & & & & & \\
\hline & Gaussian & & & & & ? & \\
\hline \multirow{9}{*}{ Proposed } & IPEC & & & & 0 & & \\
\hline & QF 50 & & & & & & \\
\hline & $\begin{array}{l}\text { JPEG } \\
\text { QF 70 }\end{array}$ & & & & & & \\
\hline & JPEG2000 & & & & & & \\
\hline & JPEG2000 & & & & & & \\
\hline & CR 3 & & & & & & \\
\hline & Average & & & & & & \\
\hline & Gaussian & & & & & & \\
\hline & Filtering & & & & & & \\
\hline
\end{tabular}


nts value. The experiment results shows that the proposed method has proper watermarked images quality above $38 \mathrm{~dB}$. In term of robustness against compression and filtering attacks, the proposed method has outperform the previous method by Mohan and Kumar which perform SVD directly on image pixel value. IHWT is able to perform down sampling on image which in turn increase the robustness of watermark image and reduce the computational complexity in extraction of watermark. Moreover, the IHWT has finite integer value which can avoid reversibility problem in wavelet based watermarking system, making it suitable for further development of reversible watermarking system.

\section{Acknowledgement}

The authors would like to thank to Institute of Research and Community Services (LPPM), Universitas Dian Nuswantoro for providing financial support on this study by Research Grants Scheme (021/A.35-02/UDN.09/X/2015)

\section{References}

[1] M. Ali, C. W. Ahn, M. Pant, and P. Siarry, "An image watermarking scheme in wavelet domain with optimized compensation of singular value decomposition via artificial bee colony,” Inf. Sci. (Ny)., vol. 301, pp. 44-60, 2015.

[2] N. Muhammad and N. Bibi, "Digital image watermarking using partial pivoting lower and upper triangular decomposition into the wavelet domain,” IET Image Process., vol. 9, no. 9, pp. 795-803, 2015.

[3] N. M. Makbol and B. E. Khoo, “A new robust and secure digital image watermarking scheme based on the integer wavelet transform and singular value decomposition," $\mathrm{Di}$ git. Signal Process. vol. 1, no. 134, pp. 1-14, 2014.

[4] V. Singh, R. Kumar, and A. Ojha, "Significant region based robust water-marking scheme in lifting wavelet transform domain," Expert Syst. Appl., vol. 42, no. 21, pp. 81848197, 2015.

[5] C.-C. Lai and C.-C. Tsai, "Digital Image Watermarking Using Discrete Wavelet Transform and Singular Value Decom-position,” IEEE Trans. Instrum. Meas., vol. 59, no. 11, pp. 3060-3063, 2010.

[6] S. Rao V, “A DWT-DCT-SVD Based Digital Image Watermarking Scheme Using Particle Swarm Optimization,” in 2012 IEEE Students' Conference on Electrical, Electronics and Computer Science, 2012, pp. 10-13.
[7] S. D. Lin, “A robust DCT-based watermarking for copyright protection," IEEE Trans. Consum. Electron, vol. 46, no. 3, pp. 415421, 2000.

[8] J. C. Patra, J. E. Phua, and C. Bornand, “A novel DCT domain CRT-based water-marking scheme for image authentication surviving JPEG compression,” Digit. Signal Process, vol. 20, no. 6, pp. 1597-1611, 2010.

[9] C. Li, Z. Zhang, Y. Wang, B. Ma, and D. Huang, "Dither modulation of significant amplitude difference for wavelet based robust watermarking," Neurocomputing, vol. 166, pp. 404-415, 2015.

[10] K. Loukhaoukha and J.-Y. Chouinard, "Hybrid watermarking algorithm based on SVD and lifting wavelet transform for ownership verification," in 2009 11th Canadian Workshop on Information Theory, 2009, no. 1, pp. 177-182.

[11] M. Botta, D. Cavagnino, and V. Pomponiu, "A modular framework for color image watermarking,” Signal Processing, vol. 119, pp. 102-114, 2016.

[12] N. Raftari and A. M. E. Moghadam, "Digital image steganography based on Integer Wavelet Transform and assignment algorithm," Proc.- 6th Asia Int. Conf. Math. Model. Comput. Simulation, AMS 2012, pp. 87-92, 2012.

[13] P. W. Adi, F. Z. Rahmanti, and N. A. Abu, "High Quality Image Steganography on Integer Haar Wavelet Transform using Modulus Function,” in 2015 International Conference on Science in Information Technology (ICSITech), 2015, pp. 79-84.

[14] J. Xu, a. H. Sung, P. Shi, and Q. Liu, “JPEG compression immune steganography using wavelet transform," Int. Conf. Inf. Technol. Coding Comput. 2004. Proceedings. ITCC 2004. vol. 2, pp. 0-4, 2004.

[15] N. A. Abu, P. W. Adi, and O. Mohd, "Robust Digital Image Steganography within Coefficient Difference on Integer Haar Wavelet Transform," International J. Video Image Process. Netw. Secur., vol. 14, no. 02, pp. $1-8,2014$.

[16] B. C. Mohan and S. S. Kumar, "A Robust Image Watermarking Scheme using Singular Value Decomposition,” J. Multimed., vol. 3, no. 1, pp. 7-15, 2008.

[17] Z. Wang, A. C. Bovik, H. R. Sheikh, and E. P. Simoncelli, "Image Image quality assessment: From error visibility to structural similarity,” IEEE Trans. Image Process., vol. 13, no. 4, pp. 600-612, 2004.

[18] Y. P. Lee, J. C. Lee, W. K. Chen, K. C. Chang, I. J. Su, and C. P. Chang, "High-payload 
34 Jurnal IImu Komputer dan Informasi (Journal of Computer Science and Information), Volume 9, Issue 1, February 2016

image hiding with quality recovery using triway pixel-value differencing," Inf. Sci. ( $\mathrm{Ny}$ ).,

vol. 191, pp. 214-225, 2012. 